\title{
LIMITES DO EXERCÍCIO DO PODER DE POLÍCIA À LUZ DOS DIREITOS FUNDAMENTAIS: ANÁLISE DAS MEDIDAS RESTRITIVAS ADOTADAS DURANTE A PANDEMIA DO COVID-19
}

\section{LIMITS ON THE EXERCISE OF POLICE POWER IN THE FACE OF THE FUNDAMENTAL RIGHTS: ANALYSIS OF RESTRICTIVE MEASURES DURING THE COVID-19 PANDEMIC}

EMERSON AFFONSO DA COSTA MOURA ${ }^{1}$

RESUMO: Os limites impostos ao poder de polícia nas restrições de direitos fundamentais no conflito entre as liberdades públicas e o interesse público nas medidas restritivas impostas durante a pandemia da COVID-19 é o tema posto em debate. Analisa-se o papel assumido pelos direitos fundamentais no Direito Administrativo após a ascensão dos Estados Constitucionais de Direito, o estudo do conteúdo e dos limites do poder de polícia na restrição dos direitos fundamentais, e, por fim, o conflito entre liberdades públicas e o interesse público nas medidas restritivas impostas durante a pandemia da COVID-19. Pretende-se demonstrar que em uma ordem constitucional, voltada a centralidade dos direitos fundamentais, o poder de polícia submeterá a um juízo de ponderação entre o interesse público e o direito fundamental envolvido, de forma a justificar a sua restrição, bem como, a limites procedimentais e substanciais para a sua aplicação.

Palavras-Chave: Poder de Polícia; Direitos Fundamentais; Restrições; Administração Pública; COVID-19.

\footnotetext{
1 Professor Permanente do Mestrado em Direito da Universidade Federal do Estado do Rio de Janeiro (UNIRIO). Professor da Pós-Graduação em Direito Administrativo da Pontifícia Universidade Católica (PUC-RJ), Universidade do Estado do Rio de Janeiro (UERJ) e da Escola de Magistratura do Rio de Janeiro (EMERJ). Professor Adjunto da Universidade Federal do Estado do Rio de Janeiro (UNIRIO) e da Universidade Federal Rural do Rio de Janeiro (UFRRJ). Doutor em Direito pela Universidade do Estado do Rio de Janeiro (UERJ). Mestre em Direito Constitucional e Especialista em Direito Administrativo da Universidade Federal Fluminense (UFF). Vice-presidente da Comissão de Direito Administrativo do Instituto dos Advogados Brasileiros (IAB). Co-Idealizador, Co-Fundador, e Diretor Acadêmico do Instituto de Direito Administrativo do Rio de Janeiro (IDARJ). E-mail: emersonacmoura@yahoo.com.br. CV: http://lattes.cnpq.br/2482762073000021.
} 
ABSTRACT: The limits imposed on police power in the restriction of fundamental rights in the conflict between public freedoms and the public interest in restrictive measures imposed by the Federal Public Administration during the COVID-19 pandemic is the subject of debate. We analyze the role assumed by fundamental rights in Administrative Law after the rise of Constitutional States of Law, the study of the content and limits of police power in the restriction of fundamental rights, and, finally, the conflict between public freedoms and the public interest in restrictive measures imposed by the Federal Public Administration during the COVID-19 pandemic. It is intended to demonstrate that in a constitutional order, focused on the centrality of fundamental rights, the police power will submit to a weighing judgment between the public interest and the fundamental right involved, in order to justify their restriction, as well as, limits procedural and substantial for its application.

KEYWORDS: Police power; Fundamental rights; Restrictions; Public Administration; COVID-19.

\section{INTRODUÇÃO}

Embora usualmente apontado como decorrência do triunfo das revoluções liberais, o Direito Administrativo Moderno dos países de matriz romanogermânica é construído a partir de uma série de categorias jurídicas, que formam uma disciplina exorbitante e denotam uma posição de superioridade em relação ao particular.

Sob os influxos de um regime jurídico-administrativo próprio voltado à persecução do interesse público se fundamenta a concessão de poderes e prerrogativas aos agentes, que permite a Administração Pública, em eventual conflito com os direitos do cidadão, sujeitá-lo à realização dos bens e valores da comunidade.

Embora usualmente reiterada pela literatura jurídica a dialética interesse público - identificado com as necessidades da coletividade - e interesse privado - nomeado como os desejos privados - inevitável que tais construções e afastam daquele modelo oitocentista de Estado e assumem nova dimensão na contemporaneidade.

Nas sociedades contemporâneas, o interesse público assume uma expressão plural para designar a complexização e especialização da multiplicidade de interesses que uma sociedade pluralística possui, que devem ser perseguidos pelo Estado como valores comunitários e se identificando muitas das vezes aos chamados interesses privados.

Neste viés, os direitos fundamentais do homem, antes relegados à categorias como direitos subjetivos do administrado, passam a ser fins perseguidos pelos Estados Constitucionais, redimensionando o fundamento e a própria finalidade 
dos poderes públicos, que abrange a proteção e promoção destes bens e valores constitucionais.

Por efeito, o tradicional conflito entre interesse público e privado resolvido no campo da dogmática ou, mais propriamente dito, do dogma - com uma supremacia apriorística, absoluta e abstrata do primeiro- acaba conduzindo, nos chamados hard cases, a maior necessidade do aplicador buscar uma justa medida e sem sacríficos absolutos de ambos interesses legítimos.

Neste caso, compete no âmbito da interpretação - seja legislativa, judicial ou administrativa - uma atividade cognitiva que permita ao aplicador extrair, a partir dos tipos legais, a norma a ser aplicada ao caso concreto buscando solver o conflito interpessoal, que é fundamento primeiro e precípuo do Direito como uma técnica de regulação social.

Assume especial relevo, no que se refere ao exercício de poderes e prerrogativas estatais que, ao limitar direitos fundamentais, demandam a necessidade de ponderação dos interesses envolvidos de forma a verificar, no caso concreto, aquele que tiver maior peso e assumirá preponderância sem que conduza a sacrifícios ilegais e desproporcionais ao outro.

Dentro da temática se destaca o poder de polícia, que naturalmente, é a prerrogativa de restringir a propriedade e liberdade para fins do interesse público e, sob a égide de um Estado Constitucional de Direito pautado pela centralidade do homem e promoção dos direitos fundamentais, não pode importar em uma restrição apriorística, absoluta e abstrata.

Busca o presente trabalho discutir os limites que podem ser considerados como impostos ao poder de polícia no que tange as restrições de direitos fundamentais, a saber, no conflito entre as liberdades públicas e o interesse público por medidas impostas pelo Estado ao particular.

Utiliza-se, como teste de hipótese, o exercício do poder de polícia pela Administração Pública Federal durante a pandemia da COVID-19 em razão da tensão evidente entre a pluralidade de bens e interesses envolvidos - que não se limitam apenas à saúde pública e liberdade privada -, já que envolvem um feixe de deveres estatais e direitos humanos.

Para tanto, analisa-se o papel assumido pelos direitos fundamentais no Direito Administrativo após a ascensão dos Estados Constitucionais de Direito, o estudo do conteúdo e dos limites do poder de polícia na restrição dos direitos fundamentais, e, por fim, o conflito entre liberdades públicas e o interesse público nas medidas restritivas durante a COVID-19.

Pretende-se demonstrar que em uma ordem constitucional voltada à centralidade dos direitos fundamentais, o poder de polícia submeterá a um juízo de ponderação o interesse público e o direito fundamental envolvido, de forma a justificar a sua restrição, bem como limites procedimentais e substanciais para a sua aplicação. 


\section{O DIREITO ADMINISTRATIVO ENTRE O INTERESSE PÚBLICO E OS DIREITOS FUNDAMENTAIS}

Embora haja certo consenso que a "pedra angular" do Direito Administrativo seja a persecução do interesse público - a par da divergência quanto a sua supremacia - a história da disciplina no Estado Moderno aponta a existência de outros fundamentos que legitimam a atuação da Administração Pública, dentre os quais, os próprios direitos fundamentais.

$\mathrm{O}$ advento do Estado Liberal de Direito é marcado pela legalidade como postulado fundamental do Direito Público, vinculando o agir estatal à legislação emanada pelo poder competente segundo as prescrições formais, independente do grau de adequação material à vontade de seus titulares (DALLARI, 1995, p. 174177), sendo alçado a parâmetro de juridicidade da Administração.

Durante um longo tempo, o princípio da legalidade assumiu a feição das teorias positivistas com estreitamento da sujeição dos poderes públicos apenas à produção normativa formal através de regras jurídicas, de modo que, na ausência de norma ou mediante a previsão do próprio tipo legal, surge o espaço de discricionariedade para a atuação administrativa.

Entretanto, o reconhecimento da normatividade da Constituição e de sua supremacia hierárquica e axiológica na ordem jurídica bem como o advento da pluralização das fontes normativas redimensionaram a juridicidade para além do fundamento positivista, adequando a expansão do Direito além da lei e dando nova configuração ao princípio da legalidade (OLIVEIRA, 2009, p. 35).

Com a elevação da Constituição a parâmetro de validade formal e material de todos os atos e normas que compõem o ordenamento jurídico, a legalidade passa a corresponder, em primeiro grau, à compatibilidade dos atos oriundos da Administração Pública com a carta magna e não com a lei ou com a espécie normativa próxima. (CANOTILHO, 1993, p. 836).

Observa-se, portanto, uma vinculação direta e imediata da atividade administrativa à Constituição independente da conformação legislativa, sem que resulte na exclusão como parâmetro de validade da atividade administrativa a regulamentação dada pelo legislador ordinário através da lei ou das demais espécies normativas adequadas (OTERO, 2003, p. 735).

A Administração Pública permanece em grau inferior adstrita à legislação, não podendo, sob a assertiva de encontrar fundamento direto na lei fundamental e a sua alegada aplicação otimizada, desvincular a atuação administrativa para além dos domínios da lei ou eventualmente contrária as suas prescrições, ignorando a deliberação promovida no âmbito infraconstitucional (BARROSO, 2003, p. 38).

A assunção pela Constituição do epicentro da ordem jurídica representa, portanto, a força motriz de consolidação das mudanças que tem sofrido o direito administrativo com a impregnação de seus institutos, normas e categorias administrativas pelos princípios e regras fundamentais, voltando sua atuação à concretização dos direitos fundamentais. 
Por efeito, a Administração Pública em geral encontra-se sob a reserva dos direitos fundamentais, de tal sorte que, no exercício de persecução do interesse público, seja no exercício precípuo da atividade administrativa, mas também de funções residuais com a atividade legislativa ou jurisdicional, há o dever específico de tutela dos direitos do homem (CANOTILHO, 1993, p. 579-580).

Isso importa na execução apenas de leis adequadas formal e materialmente aos preceitos constitucionais consagradores daqueles direitos, além da interpretação de suas cláusulas gerais e conceitos jurídicos indeterminados, bem como exercício da discricionariedade administrativa, em conformidade com os direitos fundamentais (CANOTILHO, 1993, p. 584-585).

Portanto, se no século XIX a lei e a fruição da liberdade individual se tornaram núcleo do Direito Público com o reconhecimento do dever estatal de não intervir na autonomia individual, no século $X X$, a Constituição e o reconhecimento dos direitos sociais, impõem ao Estado deveres positivos e obrigações que devem corresponder aos direitos e pretensões do administrado (TÁCITO, 1993, p. 1-2).

A dogmática administrativa, que se estrutura em premissas teóricas que refletiam a tensão dialética entre a lógica da autoridade - exteriorizada na continuidade e preservação das instituições - e a lógica da liberdade - antevista na promoção das conquistas liberais e democráticas-, se submete a transformações com fins a realização dos direitos do homem.

Assentou-se em um modelo formal subordinativo de relação entre Administração Pública e o administrado de natureza notadamente unilateral, subordinativo e esporádico com o predomínio da coerção e da exclusividade estatal na definição e persecução dos interesses sociais e equidistância e hierarquia em relação aos interesses particulares (MOREIRA NETO, 2001, p. 26-27).

Porém, com ascensão axiológica dos direitos fundamentais, apreende-se uma nova ordem consensual de relação entre Administração e Cidadão, com cunho eminentemente multilateral, coordenativo e contínuo, baseado na centralidade do indivíduo e na ampliação dos espaços que propiciem sua participação na gestão pública e a durabilidade das relações administrativas (BAPTISTA, 2003. p. 128-130).

Envolve a orientação da persecução estatal à promoção dos direitos e garantias do homem, reordenando além da relação entre a Administração Pública e o Administrado ao eixo nodal da dignidade da pessoa humana e a persecução do desenvolvimento e dos direitos fundamentais encontrando na regulação estatal e nos serviços públicos seus instrumentos. (JUSTEN FILHO, 2009, p. 150-152)

A intervenção do Estado na atividade econômica não se limita à condução dos agentes econômicos a uma situação de mercado ideal com proteção da concorrência e do lucro, mas deve ter por finalidade conduzir os esforços públicos e privados ao desenvolvimento e ao bem-estar social (MOREIRA, 2006, p 856-857 e 868).

Os serviços públicos tornam-se instrumentos para a realização dos direitos fundamentais ao garantir, através do oferecimento de bens e utilidades essenciais, as prestações positivas necessárias à realização de um núcleo mínimo necessário à 
preservação da dignidade da pessoa humana e realização dos direitos fundamentais.

O pilar que sustenta o regime jurídico-administrativo - o interesse público também diante da supremacia axiológica da Constituição e a centralidade assumida pelos direitos fundamentais é reordenado a fim de garantir a concretização dos referidos preceitos, já que correspondem, igualmente, aos objetivos da sociedade consagrados na lei fundamental.

Sob um ângulo, se descarta uma noção de supremacia do Interesse Público estática como a superioridade do interesse coletivo sobre o interesse particular, que permite a restrição de direitos e confere um complexo de privilégios à Administração Pública que a habilitaria ao desempenho na persecução dos objetivos socialmente almejados (MEIRELLES, 2005, p. 49).

De tal noção não decorre uma ilimitada esfera de liberdade da Administração Pública na submissão dos interesses privados sob o fundamento de interesses públicos, pois como visto, em um Estado de Direito, os direitos fundamentais têm como finalidade justamente conter o poder estatal contra o arbítrio e submeter os poderes públicos ao respeito aos cidadãos.

Assim, a concepção do interesse público deve ser vista não a partir de poder de império que sempre gozou a Administração Pública, mas na sua atuação voltada à concretização dos direitos fundamentais que reordenam a persecução dos bens e valores essenciais para a coletividade (BAPTISTA, 2011, p. 52-53).

Em uma ordem constitucional voltada à promoção dos direitos fundamentais, não se pode considerar uma hierarquia absoluta e em abstrato do interesse público sobre o privado, mas o reconhecimento da garantia dos direitos e garantias fundamentais, permitida sua excepcional restrição pelo interesse público desde que justificada a sua limitação.

Portanto, de uma disciplina de autoridade, que pressupunha uma relação vertical entre Estado e cidadão, volta-se o Direito Administrativo como exercício de persecução do interesse público, garantir em prol dos cidadãos a melhor satisfação possível de seus direitos fundamentais (ARAGÃO, 2005, p. 4).

Ademais, considerar a supremacia do interesse público sobre o privado como um princípio que prevalece in abstracto e de forma absoluta em todos os casos não se adequa à sua natureza, uma vez que não se sujeita à ponderação no caso concreto e não se compatibiliza com outros postulados normativos, como a proporcionalidade e concordância prática (ÁVILA, 2005, p. 186-190).

Não se questiona a existência de um princípio implícito de prevalência do interesse público, mas o seu conteúdo, pois em sua concepção tradicional coloca a Administração Pública numa posição privilegiada em face do cidadão (SARMENTO, 2005, p. 27 e 25), permitindo sem esforço argumentativo in concreto a submissão dos direitos fundamentais ao poder estatal (BORGES, 2007, p. 3).

Além disso, os interesses públicos e privados guardam uma conexão de sentido que impõe a ideia de mútua complementação e autodelimitação, que não os tornam 
antagônicos ou conflitantes, mas que os fazem se complementar e harmonizar, de tal sorte que a realização de um importa na tutela do outro (NEGREIROS, 2009, p. 337).

Porém, existindo eventuais conflitos, sua solução in abstrato decorre do poder constituinte originário que pode delimitar as hipóteses em que prevalecerão os interesses privados - na tutela dos direitos fundamentais frente ao Estado - ou os interesses públicos - em atenção a proteção dos fins Estatais em face dos direitos individuais (SCHIER, 2004, p. 148-149).

Pode ainda a Constituição determinar que o conflito dos interesses privados com o interesse público seja delimitado através do legislador ordinário, se sujeitando a conformação legislativa à observância do princípio da proporcionalidade e à proibição do excesso, garantindo o núcleo essencial dos direitos fundamentais.

Não obstante, não sendo delimitada pela própria Constituição, cabe à própria Administração Pública ou ao Judiciário, mediante a ponderação de interesses, verificar no caso concreto, a partir dos elementos que integram o âmbito normativo do interesse público e privado em comento, qual deverá prevalecer, se adequando à ordem jurídico-constitucional (BINENBOJM, 2014, p. 151 e 167) (SARMENTO, 2005, p. 103 e 115).

Razão pelo qual parece mais adequado sustentar um princípio do interesse público ou da prossecução do interesse público, que orienta a atividade administrativa, mas que, em eventual conflito, se sujeitará à ponderação com o direito fundamental ao qual pretende-se restringir, determinando qual, no caso concreto, possui pelos argumentos mais peso (MOURA, 2014).

Outra transformação produzida pelos direitos fundamentais na disciplina se refere à discricionariedade administrativa, ou seja, o espaço de liberdade decisória concedida à Administração Pública na eleição entre os indiferentes jurídicos na atribuição concedida pela norma jurídica e de acordo com a formulação dos juízos de conveniência e oportunidade (DI PIETRO, 1990, p. 92).

Embora se adéque à necessária dinâmica da atividade administrativa - em um contexto de multiplicidade e complexidade do interesse público que escapa à previsibilidade do legislador - não significa que há um campo insindicável de escolha na atuação administrativa, mas se sujeita aos limites pela Constituição, em especial, os direitos fundamentais (MELLO, 1992, p. 44-48).

A vinculação da Administração Pública à concretização dos direitos fundamentais impõem uma atuação negativa - de abstenção ou tolerância no exercício das liberdades pelo seu titular - mas também uma atividade positiva - de oferecimento de bens e serviços necessários a fruição dos bens e interesses fundamentais (BARCELLOS, 2006, p. 37).

Ocorre, inclusive, com a definição de prioridades e dispêndios, com a implementação de um sistema constitucional de financiamento, que prevê fontes de custeio para a execução de programas e ações estatais necessárias para a 
implementação dos direitos fundamentais, em especial, dos direitos sociais (SCAFF, 2007, p. 33-34).

A concepção da discricionariedade administrativa de uma ampla esfera de escolha na persecução do interesse público não sujeito a controle pelos poderes públicos passa a um campo de concretização dos direitos fundamentais, mediante a ponderações proporcionais e razoáveis entre os bens e interesses constitucionais, sujeita a controle exercido pelo Poder Judiciário (CUNHA, 2005, p. 168-172).

Envolve a submissão do espaço decisório ao sistema de direitos fundamentais, que passam a orientar os juízos de valoração do administrador pelos critérios de razoabilidade e isonomia, assegurando a congruência da decisão administrativa ao interesse constitucional ou legal e o impedimento de sua tradução em arbitrariedade (BINENBOJM, 2010, p. 237).

Note, portanto, que a ascensão normativa da Constituição e reconhecimento da centralidade dos direitos fundamentais na ordem jurídica, promoveu sensíveis transformações na disciplina administrativa impondo uma releitura de suas normas, institutos e categorias tidos como essenciais.

Isso envolve o exercício dos poderes administrativos que, antes vistos como prerrogativas capazes de restringir os direitos fundamentais de forma ilimitada em nome do interesse público, irão se sujeitar a limites impostos pela ordem jurídicoconstitucional de forma a preservar o núcleo intangível dos direitos subjetivos.

O tema será tratado a seguir.

\section{O PODER DE POLÍCIA E OS LIMITES NA RESTRIÇÃO DOS DIREITOS FUNDAMENTAIS}

Corresponde o poder de polícia, em seu sentido tradicional, à faculdade que dispõe a Administração Pública para condicionar ou restringir o uso ou gozo de bens, atividades e direitos individuais, em razão de benefício da própria coletividade ou do próprio Estado, em nome do bem-estar social, do desenvolvimento ou da segurança nacional (MEIRELLES, 2005, p. 131).

Embora usualmente associado ao exercício da função administrativa, compreende o sistema total de regulação da ordem social interna, que busca preservar a ordem pública e decorre do ius imperium que possui o Estado para submeter todos aqueles que estejam sob o seu domínio territorial (MEIRELLES, 2005, p. 132).

Na tensão promovida entre autoridade da Administração Pública - com a concessão de prerrogativas e poderes - e a liberdade individual - com a sua sujeição a direitos do indivíduo - se situaria o poder de polícia, no condicionamento do último em favor do primeiro, em razão da relatividade dos direitos fundamentais (DI PIETRO, 2014, p. 122).

Assim, sistematiza-se o poder de polícia como decorrente da supremacia geral - de submissão de qualquer administrado decorrente da lei - ou, ainda, de uma relação especial de sujeição - quando assentada em relação específica ao qual se 
sujeita - como decorre com os servidores públicos ou concessionários (BANDEIRA DE MELLO, 2009, p. 817).

Uma vez que há a ampliação horizontal do complexo de atividades ao qual se incumbe o Estado-Administração, não é possível delimitar o seu objeto como tentou a norma tributária (BRASIL, Lei no 5.172 de 25 de outubro de 1996, Art. 78) mas tende a doutrina seu fundamento na proteção de conceitos jurídicos indeterminados, às vezes passíveis de assumir cunho autoritário, como a segurança nacional ou bons costumes (MEIRELLES, 1991, p. 134).

Alguns autores buscam delimitar as áreas de atuação que abrangeriam a polícia de costumes, de comunicação, sanitária, de viação, de comércio e indústria, das profissões, ambiental, de estrangeiro e edilícia, inserido em grandes campos de atuação de interesse público: a segurança, a salubridade, o decoro e a estética (MOREIRA NETO, 2001, p. 445).

Tradicionalmente, é apontado como limites do poder de polícia administrativa o próprio respeito à legalidade e à finalidade, ou seja, a existência de interesse social que justifique a restrição à parcela de seu direito fundamental em prol do bem comum ou interesse coletivo, já que a sociedade oferece benefícios públicos (MEIRELLES, 1991, p. 135).

No que tange à legalidade, significa o respeito imposto pela própria lei à prática do ato administrativo (BRASIL, Lei oㅜ 9.873, de 23 de novembro de 1999. Art. 1), bem como a observância de seus requisitos de competência, forma, fins e mesmo com relação aos motivos ou ao objeto determinado pela norma jurídica, sob pena das sanções da lei (DI PIETRO, 1990, p. 129).

Já no campo da finalidade é a observância da própria ratio da atividade administrativa, ou seja, o atendimento ao interesse público legalmente qualificado, de forma que o afastamento da finalidade pública incidirá em desvio de poder, acarretando a nulidade do ato de polícia com as repercussões nas esferas civil, penal e administrativa (DI PIETRO, 1990, p. 130).

Note, porém, que a doutrina moderna indica que a atividade restritiva do Estado aos direitos fundamentais deve se condicionar em uma série de princípios e regras de Direito, como a razoabilidade da conduta, a isonomia de tratamento e o respeito ao âmbito legítimo reservado às ações privadas dos homens que não violam a ordem pública. (CASSAGNE, 2002, p. 326)

Deve ser orientada pelo princípio da subsidiariedade de forma que a intervenção do Estado, no exercício do poder de polícia, deve ser apenas nos casos em que os membros da sociedade atuem de forma incapaz de garantir o respeito ou concretização dos interesses da comunidade (CASSAGNE, 2002, p. 327).

Neste caso, uma vez que o Poder de Polícia visa ao razoável equilíbrio entre os direitos individuais e os interesses da coletividade, deve condicionar os direitos individuais, mas não os tornar inservíveis, ou seja, deve regulamentar a função social já inerente ao conteúdo do direito, se alcançar o seu conteúdo mínimo, descaracterizar-se-á (ARAGÃO, 2013, p. 180). 
Liga-se, portanto, à noção de núcleo essencial do direito fundamental de maneira que, a título de realização do bem ou interesse coletivo, não pode ser capaz de alcançar a essencialidade do direito subjetivo, sob pena da restrição importar anulação, o que configura desrespeito à ordem jurídico-constitucional e abuso pelo agente público (DIEZ, 1997, p. 187).

Assim, nos sistemas constitucionais onde estão consagrados os direitos fundamentais da pessoa humana, o princípio vigente é favor libertatis, de forma que a restrição por interesse público é excepcional, sendo vedado o seu uso indiscriminado das medidas quando outros podem ser utilizados (CASSAGNE, 2002, p. 343).

Neste viés, submete-se a restrição do poder de polícia à observância do princípio da proporcionalidade, exigindo que a medida seja adequada - capaz de atingir o bem comum almejado - necessária - inexistir outra menos gravosa para tal fim - e proporcional - relação necessária entre a limitação ao direito individual e o bem almejado.

A limitação dos direitos fundamentais aos fins de promoção do bem comum decorre da subordinação razoável do interesse privado ao público, que em conflito apenas irá se sobrepor quando o bem comum se tornar necessário e não for alcançável por outro meio e sem resultar a destruição do direito fundamental (DIEZ, 1997, p. 188).

Tal juízo de proporcionalidade e razoabilidade deve obedecer a um processo objetivo e racional de valoração justificada e adequada dos antecedentes necessários, a proporção adequada à finalidade legal da medida para a prática do ato de polícia com a restrição da liberdade individual (DIEZ, 1997, p. 203-204).

Note que isto envolve o respeito à cláusula do due process of law, ao menos em seu aspecto substancial, a saber a observância da razoabilidade, proporcionalidade e inteligibilidade da decisão do ato de polícia, de forma a permitir o controle pela sociedade e poderes públicos.

Por fim, aponta a doutrina, também, a necessidade das sanções de polícia estarem afinadas em sua intensidade com a gravidade da infração a que visam reprimir (ARAGÃO, 2004, p. 181), sob pena de violar a razoabilidade, impondo gravame superior ao desrespeito à ordem jurídico-constitucional e, portanto, fora da legalidade.

Note-se que o poder de polícia pode ser administrativo - através da aplicação da lei ao caso concreto, mediante medidas repreensivas e preventivas - e o poder de polícia legislativo - que decorre de normas gerais e abstratas dirigidas a restringir de forma abstrata dado comportamento humano. (DI PIETRO, 1990, p. 126)

$\mathrm{Na}$ ordem jurídico-brasileira, a restrição e condicionamento das liberdades e direitos fundamentais devem ser tidos como uma exceção às suas respectivas afirmações e garantias constitucionais, daí a razão pela qual somente possam ser 
exercidos sob estrita reserva legal, ou seja, por via do poder de polícia normativo, função reservada ao legislador (MOREIRA NETO, 2001, p. 439).

Neste tocante, o exercício poder de polícia com a restrição aos direitos fundamentais deve ser interpretado não de forma apriorística, absoluta e abstrata, mas ao revés, deve ser considerada à luz do caso concreto e ter caráter atual e relativo, de forma que deva sustentar a excepcionalidade da restrição da medida.

O tema será tratado a seguir.

\section{RESTRIÇÕES DO PODER DE POLÍCIA PELA ADMINISTRAÇÃO PÚBLICA FEDERAL DURANTE A PANDEMIA DO COVID-19}

Foi editada em 06 de fevereiro de 2020 a lei federal de $n^{0}$ 13.979, que dispõe sobre as medidas a serem adotadas para enfrentamento da emergência de saúde pública de importância internacional decorrente do coronavírus responsável pelo surto de 2019 com objetivo de proteção da coletividade.

Para a tutela do interesse público - saúde pública - foram previstas medidas restritivas aos interesses ditos privados - liberdades fundamentais - dentre as quais isolamento, quarentena, realização compulsória de exames, testes, vacinas e afins, exumação, necropsia, cremação e manejo de cadáver e estrição excepcional e temporária de entrada e saída do País (BRASIL, Lei Federal no 13.979/2020. Art. 3).

As liberdades públicas correspondem a direitos humanos-fundamentais de primeira geração com distintas dimensões, abrangendo desde a liberdade de ir e vir até mesmo a liberdade de manifestação, de crença e de pensamento, que exigem do Estado, em princípio, um comportamento negativo, ou seja, uma abstenção, para sua realização.

Sob a ótica da teoria das restrições dos direitos fundamentais, no âmbito normativo, a limitação aos direitos que compõem essa categoria pode se dar a partir da restrição contida na própria Constituição da República ou quando permitida ao legislador infraconstitucional mediante ou sem autorização. (MOREIRA, 2009, p. 96-98)

Embora se sujeitem às restrições em uma ordem plural, tais limitações não podem ser realizadas de forma a esvaziar seu conteúdo, tanto que a Constituição, ao conferir-lhes tratamento, também reservou-lhes proteção como cláusula pétrea constante do elenco dos direitos fundamentais.

Por efeito, o exercício do poder de polícia, ao determinar restrições além daquelas previstas na Constituição Federal, não pode exacerbar os limites violando seu núcleo essencial, de modo que o sacrifício do interesse "privado" - liberdade privada - não signifique uma submissão integral e exclusão em prol do interesse público.

A proteção da coletividade, como um conceito jurídico aberto e indeterminado, tem que estar condicionada e preenchida por um legítimo e razoável interesse constitucional para ser aplicada. É inadmissível que uma decisão política ou 
jurídica se fundamente tão somente no interesse público, ignorando os direitos fundamentais. (MOREIRA, 2009, p. 96-98)

Ao revés, os direitos fundamentais em conflito devem ser resolvidos no âmbito da ponderação de interesses, de modo que nenhuma norma pode ser absoluta e plenamente exercitável (MOREIRA, 2009, p. 96-98), uma vez que o peso circunstancial dos bens jurídicos será mensurado a partir de uma técnica interpretativa aplicada à situação, à luz da Constituição e da moralidade social (PEREIRA, 2006, p. 264).

Uma vez que na lei o exercício do poder de polícia normativo com a imposição de restrição à liberdade e propriedade do particular ocorre de forma geral, a rigor, sem considerar aspectos concretos, enseja que, na atividade de poder de polícia administrativo, haja uma ponderação pelo agente público da proporcionalidade e razoabilidade da adoção da medida.

Não obstante, determina a referida lei critérios para o exercício deste poder de polícia, a saber: (i) científico, com a sujeição apenas com base em evidências científicas e em análises sobre as informações estratégicas em saúde; (ii) temporal, a ser limitadas no tempo e no espaço ao mínimo indispensável à promoção e à preservação da saúde pública (BRASIL, Lei Federal no 13.979/2020. Art. 3 §1º).

Quanto ao primeiro critério, ao sujeitar o exercício do poder de polícia a critérios subjetivos, se atende uma dimensão substancial do devido processo legal, onde cada decisão de poder no Estado Republicano e de Direito deve ser de acordo com um processo objetivo e racional que legitima a atuação estatal.

O Supremo Tribunal Federal já fixou que a referida norma, ao tratar a tomada de providências a partir de dados científicos, aponta uma determinação pelo Poder Legislativo que afasta a aplicação de critério que a Administração Pública eleja de forma discricionária para a situação, ignorando os dados científicos. (BRASIL, Supremo Tribunal Federal. ADI 6343 MC-Ref/DF, 2020)

Coaduna com o dever geral de motivação imposta à Administração Pública pelas disposições sobre segurança jurídica e eficiência na criação e na aplicação do direito público da Lei de Introdução as Normas do Direito Brasileiro, que exige a demonstração da necessidade e a adequação da medida imposta, inclusive em face das possíveis alternativas (BRASIL, Lei 13.655/2018. Art. 2º).

Tanto que fixou como erro grosseiro para fins de responsabilização do agente público qualquer atuação do Estado-Administração durante a pandemia do COVID-19 que não observe standards, normas e critérios científicos-técnicos, de organizações e entidades internacional e nacionalmente conhecidas, o que atende o dever de precaução e prevenção administrativa. (BRASIL, Supremo Tribunal Federal, ADI $6421 \mathrm{MC} / \mathrm{DF}, 2020$ )

Demanda o legislador um juízo de racionalidade - com a apresentação das bases científicas e informações estratégicas em saúde - de proporcionalidade - com a demonstração do trinônimo adequação-necessidade-proporcionalidade em sentido 
estrito das medidas adotadas - razoabilidade - considerando o razoável à luz do contexto e outras medidas.

Tais elementos ficam claros, também, no critério temporal, que, ao limitar no tempo e no espaço ao mínimo indispensável à promoção e à preservação da saúde pública, reforça a excepcionalidade das restrições relativas ao exercício do poder de polícia e submete a um juízo de proporcionalidade e razoabilidade na definição do necessário à proteção do interesse público.

Na ponderação entre os interesses públicos e privados envolvidos na aplicação do poder de polícia durante a COVID-19, a própria lei, buscando evitar o sacrifício dos direitos fundamentais, determina que as pessoas afetadas pela restrição conservam o direito à informação, o direito à tratamento gratuito e o pleno respeito a sua dignidade e direitos. (BRASIL, Lei Federal no 13.979/2020. Art. $3 \S 2^{\circ}$ )

Desta forma, coaduna a referida lei com o crescente movimento de reconhecimento de mais do que um dever negativo - de abstenção de violação há, também, um dever positivo - de concretização - dos direitos fundamentais pela Administração Pública, o que demanda ponderação em abstrato e concreto no conflito entre interesses públicos e privados.

\section{CONCLUSÃO}

Embora o Direito Administrativo e o Direito Constitucional tenham assumido trajetórias distintas após as revoluções liberais, tem se observado uma crescente aproximação após o reconhecimento da centralidade da constituição na ordem jurídica, orientando a criação, interpretação e aplicação das categorias, institutos e normas jurídico-administrativas.

Sob tal viés, sustentar um regime jurídico-administrativo pautado em uma supremacia apriorística, absoluta e abstrata de um interesse público sobre os interesses supostamente privados é ignorar a pluralidade de bens, interesses e valores constitucionais, que devem ser perseguidos e tornam os direitos fundamentais igualmente interesses a serem tutelados.

Tal tensão entre a pluralidade de valores que a Administração Pública deve concretizar pode ser observada no que tange o exercício do poder de polícia, que se antes era tido como um poder amplo dentro da legalidade de limitar propriedade ou liberdade, passa a se sujeitar à ponderação que justifique o peso maior no caso concreto em relação aos direitos fundamentais.

Durante a pandemia da COVID-19, essa tensão entre interesses públicos e privados, saúde pública e liberdade privada denota um hard case, que demanda na adoção de medidas restritivas pela Administração Pública um juízo de ponderação dos interesses envolvidos capaz de identificar aquele que possui maior peso no caso concreto sem sacrifícios do outro.

Neste compasso, a lei federal de no 13.979/2020 aponta critérios que atribuem racionalidade, razoabilidade e proporcionalidade no exercício do poder de polícia e demonstram que, na tensão entre direitos fundamentais e poder de polícia, é 
possível encontrar uma justa medida, que garanta o atendimento dos valores de uma ordem plural.

\section{REFERÊNCIAS}

ARAGÃO, Alexandre Santos. Direito dos Serviços Públicos. 2 ed. Rio de Janeiro: Forense, 2005.

ÁVILA, Humberto. Repensando o "Princípio da Supremacia do Interesse Público Sobre o Particular". In: SARMENTO, Daniel (Org). Interesses Públicos vs. Interesses Privados: Desconstruindo o Princípio de Supremacia do Interesse Público. Rio de Janeiro: Lumen Juris, 2005.

BAPTISTA, Patrícia. Transformações do Direito Administrativo. Rio de Janeiro: Renovar, 2003.

BAPTISTA, Isabelle de. O princípio da supremacia do interesse público sobre o privado: uma análise à luz dos direitos fundamentais e do Estado Democrático de Direito. Belo Horizonte: Fórum Administrativo, ano 11, n. 130, 2011.

BARBOSA, Ruy. O direito de reunião. Revista dos Tribunais. São Paulo, n. 26, v. 7, 1918.

BARCELLOS, Ana Paula de. Constitucionalização das Políticas Públicas em Matéria de Direitos Fundamentais: O Controle Político-Social e o Controle Jurídico no Espaço Democrático. In: Revista de Direito do Estado. Ano 1. n. 3. 2006.

BARROSO, Luís Roberto. O direito constitucional e a efetividade de suas normas: Limites e possibilidades da Constituição brasileira. 7. ed. Rio de Janeiro: Renovar, 2003.

BECHARA, Ana Elisa Liberatore S. Liberdade de expressão e manifestações populares no âmbito democrático. Boletim IBCCrim, São Paulo, v. 21, n. 249, ago., 2013.

BINENBOJM, Gustavo. Uma teoria do direito administrativo: direitos fundamentais, democracia e constitucionalização. 3. ed. Rio de Janeiro: Renovar, 2014.

BINENBOJM, Gustavo. A Constitucionalização do Direito Administrativo no Brasil: Direitos Humanos e Democracia como Fundamentos de Legitimidade e 
Elementos Estruturantes da Dogmática Administrativa. In: NALINI, José Renato. CARLINI, Angélica (Coord). Direitos Humanos e Formação Jurídica. Rio de Janeiro: Forense, 2010.

BORGES, Alice Gonzales. Supremacia do Interesse Público: Desconstrução ou Reconstrução? Revista Diálogo Jurídico. Salvador, n. 15, p. 3, 2007.

CANOTILHO, J. J. Gomes. Direito Constitucional. 6. ed. Coimbra: Almedina, 1993.

CASSAGNE, Juan Carlos. Derecho Administracion. Buenos Aires: Abelado Perrot, 2002.

CUNHA, Rubem Dário Peregrino. A juridicização da discricionariedade administrativa. Salvador: Vercia, 2005.

DALLARI, Dalmo de Abreu. Elementos de teoria geral do estado. 19. ed. São Paulo: Saraiva, 1995.

DIEZ, Manuel Maria. Manual de Derecho Administrativo. 2. ed. Buenos Aires: Plus Ultra, 1997.

DI PIETRO, Maria Sylvia Zanella. Da Discricionariedade Administrativa. São Paulo: Atlas, 1990.

DI PIETRO. Direito Administrativo. São Paulo: Atlas, 2014

FRANÇA, Vladimir da Rocha. Direito de reunião pacífica na Constituição Federal. Revista de Direito Constitucional e Internacional. Revista dos Tribunais, São Paulo, n. 61, v. 15, 2007.

FUX, Luiz. O direito de reunião na Constituição Federal de 1988. In: BRASIL, Supremo Tribunal Federal (STF). A Constituição de 1988 na visão dos Ministros do Supremo Tribunal Federal: edição comemorativa. Brasília: Supremo Tribunal Federal, 2013.

HARVEY, David. A liberdade da cidade. In: MARICATO, Ermínia (Coord.).

Cidades rebeldes: passe livre e as manifestações que tomaram as ruas do Brasil. 1. ed. São Paulo: Boitempo: Carta Maior, 2013. 
JUSTEN FILHO, Marçal. O Direito Administrativo de Espetáculo. Fórum Administrativo - Direito Público, Belo Horizonte, ano 9, n. 100, p. 150-152, jun. de 2009

LIMA, Venício A. de. Mídia, rebeldia urbana e crise de representação. In: MARICATO, Ermínia (Coord.). Cidades rebeldes: passe livre e as manifestações que tomaram as ruas do Brasil. 1. ed. São Paulo: Boitempo: Carta Maior, 2013.

MAIOR, Jorge Luiz Solto. A vez do direito social e da descriminalização dos movimentos sociais. In: MARICATO, Ermínia (Coord.). Cidades rebeldes: passe livre e as manifestações que tomaram as ruas do Brasil. 1. ed. São Paulo: Boitempo: Carta Maior, 2013.

MARTINS JUNIOR, Wallace Paiva. Transparência Administrativa, Publicidade, Motivação e Participação Popular. São Paulo: Saraiva, 2004.

MEIRELLES, Hely Lopes. Direito Administrativo Brasileiro. 30. Ed. Atual. por Eurico de Andrade Azevedo, Délcio Balestero Aleixo, José Emmanuel Burle Filho. Malheiros: São Paulo, 2005.

MELLO, Celso Antonio Bandeira de. Discricionariedade e Controle Jurisdicional. São Paulo: Malheiros, 1992.

MOREIRA, Eduardo Ribeiro. A teoria das restrições dos direitos fundamentais. Revista de Direito Constitucional E Internacional. Revista dos Tribunais. São Paulo, ano 17, n. 69, out-dez/2009.

MOREIRA, Egon Bockmann. O Direito Administrativo da Economia e a Atividade Interventiva do Estado Brasileiro. In: OSÓRIO, Fábio Medina; SOUTO, Marcos Juruena Villela (Coord). Direito Administrativo: Estudos em Homenagem a Diogo de Figueiredo Moreira Neto. Rio de Janeiro: Lummen Juris, 2006.

MOREIRA NETO, Diogo de Figueiredo. Mutações do Direito Administrativo. 2 ed. Atual. e aum. Rio de Janeiro: Renovar, 2001.

MOURA, Emerson Affonso da Costa. Um Fundamento do Regime Administrativo Brasileiro: O Princípio da Prossecução do Interesse Público. Rio de Janeiro: Lumen Juris, 2014.

MOVIMENTO Passe Livre - São Paulo. Não começou em Salvador, não vai terminar em São Paulo. In: MARICATO, Ermínia (Coord.). Cidades rebeldes: 
passe livre e as manifestações que tomaram as ruas do Brasil. 1. ed. São Paulo: Boitempo: Carta Maior, 2013.

NEGREIROS, Teresa. Dicotomia público-privado frente ao problema de colisão de princípios in TORRES, Ricardo Lobo (Org.). Teoria dos Direitos Fundamentais. Rio de Janeiro: Renovar, 2009.

OLIVEIRA, Rafael Carvalho Rezende. A Constitucionalidade do Direito Administrativo: O Princípio da Juridicidade, a Releitura da Legalidade Administrativa e a Legitimidade das Agências Reguladoras. Lumen Juris, 2009.

OTERO, Paulo. Legalidade e Administração Pública: O sentido da vinculação administrativa à juridicidade. Coimbra: Almedina, 2003.

PEREIRA, Jane Reis Gonçalves. Interpretação constitucional e direitos fundamentais: uma contribuição ao estudo das restrições aos direitos fundamentais na perspectiva da teoria dos princípios. Rio de Janeiro: Renovar, 2006.

PEREIRA, José Matias. Manifestações sociais e os cinco pactos nacionais propostos pelo governo. Desdobramentos democráticos para o Brasil. Revista Jurídica Consulex. Brasília, Ano XVII, n. 396, jul. de 2013.

PESCHANSKI, João Alexandre. O transporte público gratuito, uma utopia real. In: MARICATO, Ermínia (Coord.). Cidades rebeldes: passe livre e as manifestações que tomaram as ruas do Brasil. 1. ed. São Paulo: Boitempo: Carta Maior, 2013.

PINHEIRO, Armando Castelar. A revolta dos centavos. Revista Jurídica Consulex. Brasília, Ano XVII, n. 396, jul. de 2013.

SARMENTO, Daniel. Interesses públicos vs. Interesses privados na perspectiva da teoria e da filosofia constitucional. In: SARMENTO, Daniel (Org). Interesses Públicos vs. Interesses Privados: Desconstruindo o Princípio de Supremacia do Interesse Público. Rio de Janeiro: Lumen Juris, 2005.

SCAFF, Fernando Facury. Como a Sociedade Financia o Estado para a Implementação dos Direitos Humanos no Brasil. In: SCAFF, Fernando Facury (org). Constitucionalismo, tributação e direitos humanos. Rio de Janeiro: Renovar, 2007. 
SCHIER, Paulo Ricardo. Ensaio sobre a Supremacia do Interesse Público sobre o Privado e o Regime Jurídico dos Direitos Fundamentais. Revista de Estudos Criminais, Ano 4, n. 13, 2004.

SECCO, Lincoln. As jornadas de junho. In: MARICATO, Ermínia (Coord.).

Cidades rebeldes: passe livre e as manifestações que tomaram as ruas do Brasil. 1. ed. São Paulo: Boitempo: Carta Maior, 2013.

TÁCITO, Caio. Proteção dos Direitos Fundamentais. Revista de Direito Administrativo, Rio de Janeiro, n. 194, out/dez 1993.

VAINER, Carlos. Quando a cidade vai às ruas. In: MARICATO, Ermínia (Coord.). Cidades rebeldes: passe livre e as manifestações que tomaram as ruas do Brasil. 1. ed. São Paulo: Boitempo: Carta Maior, 2013.

VIANA, Silvia. Será que formulamos mal a pergunta? In: MARICATO, Ermínia (Coord.). Cidades rebeldes: passe livre e as manifestações que tomaram as ruas do Brasil. 1. ed. São Paulo: Boitempo: Carta Maior, 2013.

VIDAL, Jânio Nunes. A voz das ruas como instrumento de participação política: liberdade de reunião e de manifestação no Estado Democrático de Direito. In: ROCHA, Maria Vital da; CARVALHO, Paulo Rogério Marques de (Coord.). 25 anos da Constituição de 1988: os direitos fundamentais em perspectiva. Fortaleza: Faculdade 7 de Setembro, 2014. 